\title{
Linguistic and Extra-Linguistic features of SABC indigenous language adverts: A Critical Discourse Approach.
}

\author{
Magret Jongore \\ Bindura University of Science Education, Zimbabwe \\ jongorem@gmail.com , \\ Pink Phaahla \\ University of South Africa, South Africa \\ phaanla@unisa.ac.za \\ $\&$ \\ Rose Masubelele \\ University of South Africa, South Africa \\ masubr@unisa.ac.za
}

\begin{abstract}
Discourse encompasses not only written and spoken language but visual images as well. If discourse combines visuals and images, it is important that analysis of such texts account for the special characteristics of visual semiotics; the relationship between language and images. Using Critical Discourse Analysis (CDA), this paper, unravels power relations in the electronic advertising texts such as those aired on television. The targeted television advertising discourse is characterised by sound, colour, picture, camera angle and other motion picture attributes. The paper argues that texts in general and texts as adverts are hegemonic in nature. The reproduction of a popular culture perpetuated by adverts has been noted to support the perspective that advertising drives the global media and has profound influence on the content of the media messages received and subsequently on the cultures of the recipients. The paper makes use of the McDonalds TV Seat Advert shown on SABC1.
\end{abstract}

Key terms: Discourse Approach, semiotic, advertising, media.

\section{Introduction}

There is more to advertising a message than meets the casual eye. An effective advert, like other forms of communication, works best when it strikes a chord in the needs and desires of the receiving consumer - a connection that can be both intuitive and 
highly calculated (Leiss, 1990 p.145). Television commercials use conventions of audiovisual media for conveying meaning not only through language, but also through color, visual effects and the camera angles. South Africa is dominated commercially by two languages, namely English and Afrikaans. Research has shown that if one goes shopping and buys a product, the label on it is most likely in one of those two languages. This is probably because of South Africa's historical past.

The combination of verbal text and pictures has become important in today's culture. However, the importance of this combination is not reflected in the amount of research. There is on one hand, a large and reasonable well-grounded body of linguistic technique for the study of verbal texts to proceed from, and on the other hand there is a long and venerable tradition for the study of pictures in isolation. Research into mass communicated, industrially produced texts combining verbal and visual elements is still emerging (Vestergaard \& Scroder, 1985 p.33). Thus, this research tackles the linguistic and extra-linguistic features of television (TV) adverts using Critical Discourse Analysis (CDA). This theoretical framework acts also as an analytical tool and reveals power relations inherent in the TV advertising texts.

\section{Aims and Objectives}

The paper aims at establishing the interaction between the visual and the linguistic components used in the McDonalds TV Seat advert. At the same time, it demonstrates how linguistic and visual aspects of the advert have been used strategically to control and manipulate the audience

From both the linguistic and semiological point of view (which is observed as extralinguistic features of communication), questions to deal with are how do designers of adverts pay attention to morpho-syntactic, semantic, morphological and semiological aspects of language? Adverts like other forms of communication, are created within the constraints of many factors. Manufactures of goods target consumers and customers, through their adverts. The consumers or customers, primarily South Africans as well as other international viewers who happen to access SABC 1 in their different geographical areas come from diverse cultural backgrounds. As a result, adverts seem to carry multiple layers of meanings, both at the surface level and at advanced implicit level. Leiss et al (1997) refer to these two meanings as the denotative and the connotative meanings. Leiss et al (1997 p.65 citing Hall 1980) contend that "if the audience is to decode the message in an advert adequately, advertisers had to tap the reservoirs of social and cultural knowledge maintained by the audiences and transform this into messages". What this entails is that, advertising discourse maintains the social order or the hegemony of the society.

Thus, the Critical Discourse Approach to the analysis of the McDonalds TV Seat 
advert endeavours to show how advertisers manipulate the audience. CDA also shows situations of converging to the audience as part and parcel of the general populism in adverts. Consequently, the analysis shows how consumption habits and cultural habits are consumed through the consumption of the target advert. In other words, socio-cultural influences of the community to which the advertisers and the viewers/readers of the advert belong are transformed into the advertisements themselves. Scholarship maintains that culture is the most important "environment factor" which determines how content variables, (for example, strategies, values) and executable variables (such as colour) are manipulated in advertising.

\section{Critical Discourse Analysis (CDA)}

The blending approach to TV advertising discourse can best be achieved through the use of Critical Discourse Analysis (CDA). This blending takes from the linguists and semiologist analyses. The two camps can be unified and bring to book a holistic perspective to Discourse Analysis by making use of the CDA in advert analysis. Critical Discourse Analysis (henceforth CDA) refers to an approach to the study of language use and textual practices that focuses strictly on the inter-relationship between language and power. It draws on a range of theoretical resources derived from numerous disciplinary fields (Fairclough \& Wodak (1997 p. 271-80). It is difficult to give a single definition of CDA as a research method. Indeed, rather than providing a particular process, CDA can be characterised as a way of approaching and thinking about a problem. Therefore, in the current study, it suffices to mention that CDA is called upon as both a way instituted to see through advertising texts' hidden and surface composition, and as a way of thinking.

CDA has made the study of language an interdisciplinary tool and can be used by scholars with various backgrounds, including media criticism. This, therefore, points to the fact that in television advertising, CDA comes in handy. Most significantly, it offers the opportunity to adopt a social perspective in the cross-cultural study of media texts. As Kress (1988 p.183) points out, CDA has an "Overtly political agenda" which serves to set CDA off ... from other kinds of Discourse Analysis and text linguistics, "as well as pragmatics and socio-linguistics". While most forms of Discourse Analysis aim to provide a better understanding of socio-cultural aspects of texts, CDA "aims to provide accounts of the production, internal structure, and overall organisation of texts" (Fairclough \& Wodak 1997 p.271-80). One crucial difference is that CDA "aims to provide a critical dimension in its theoretical and descriptive accounts of texts." Thus, CDA in this study is adopted as both a method and as a theoretical perspective. Figure 1 below illustrates how CDA is being utilised in this study, 


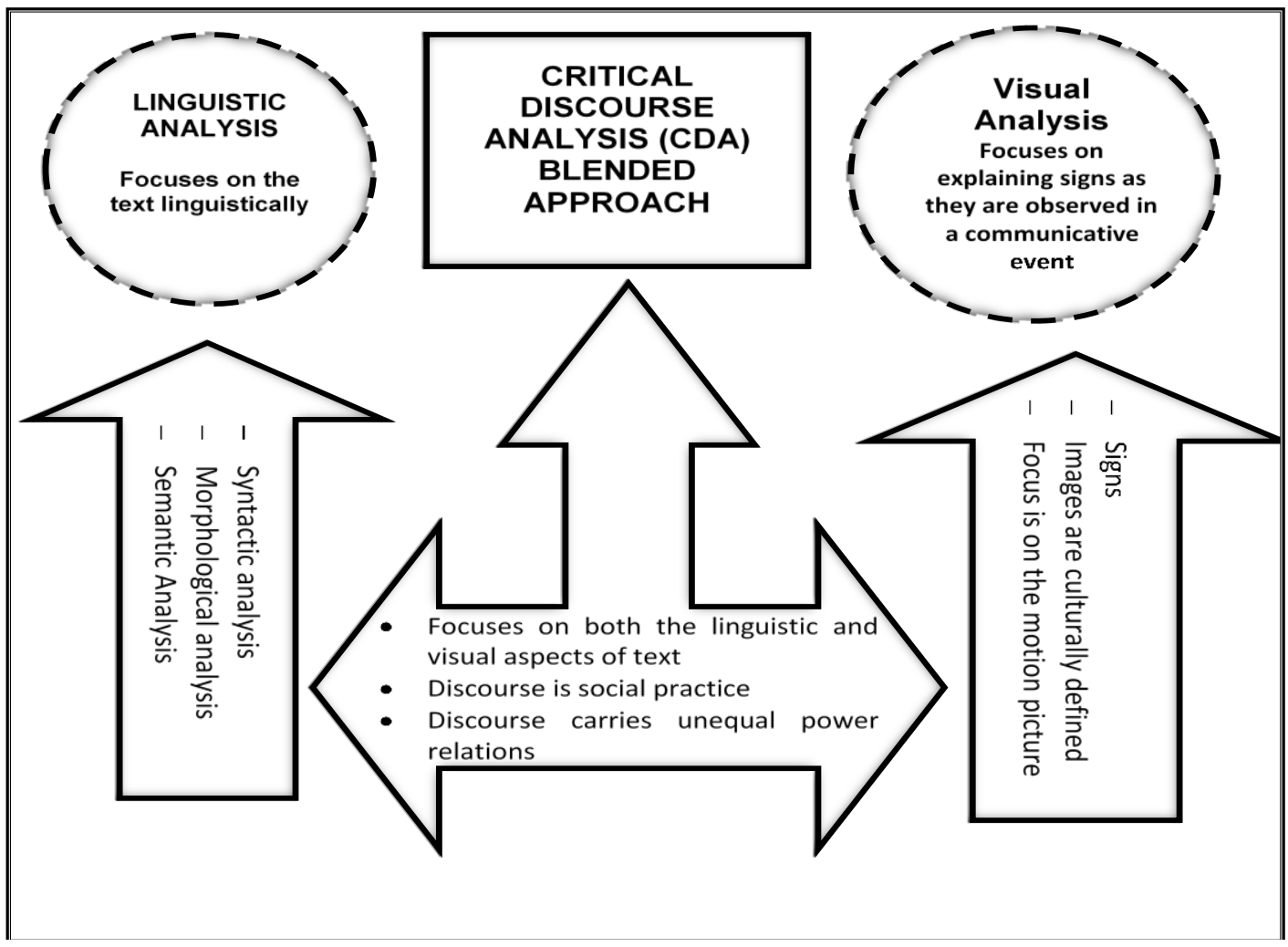

Source: Jongore (2017, p. 55)

\section{Language and power in the McDonalds TV Advert}

An outline of the McDonalds TV Seat advert is provided here on which the analysis is based.

Ngiyabonga gogo 'Thank you grandma'--- (receiving the bus fare.) (Grandma folds the right hand of the boy which she has put some coins. She then touches affectionately the shoulder of the boy and turns her back as the boy waves for the coming taxi to stop. The boy waves for the taxi to stop, about to enter the taxi he asks for the free seat.)

Baba ngicela ukuhlala eTV seat 'Sir may I sit on the free seat?'

(The taxi driver looks at the young boy accepts the request and explains to the boy the nature of the free seat.)

Kulungile mfana, awufuna ukukhokha? Kodwa kuyashisa. 'You want the free seat? Fine but it is hot'. (The taxi driver accepts the request of the boy and offers him the hot seat. The boy enters the taxi sits facing the other passengers. As soon as he sits he puts some coins in his shirt pocket for which he was supposed to 
have paid the ride. As soon as he sits the other boys start gesturing at him mocking him for occupying the hot seat. The boy starts to fidget showing visibly that the seat is hot but he is determined to continue to occupy the seat.)

Uyi TV namhlanje mfana. 'You are our TV today' (They look at him as they laugh and mock him)

Dhoba Dhoba ye-e-e-e 'Laughing at the boy, you seem not to have any choice you just have to pick what is on offer'

(After about a week of travelling seated on the hot seat, the boy looks for McDonald's outlet and finds it after searching for the outlet. He enters the outlet and goes straight where the advertised burger is sold. He gets the burger and is shown the reserved area. He goes there half way to the men's table he meets the other boys who are seated near the door eating ice cream. These boys are the same boys who have been laughing at him as he used to sit on the hot seat. The boy walks past the other school boys and make a show off gesture as he is holding a tray with the burger in it. Thus, he says to the other boys :)

.... Eh bafana... 'Hey boys'(The boy moving towards the reserved place with the burger in a tray.' (The other boys are surprised to see him with the tray they are embarrassed to the extent of wanting to seek shelter below the table. The boys make feeble noise as they look on.)

Bhekani ukuthi ngihlalelani kuTV? 'Hey boys look why I sit on TV Seat?' (Showing the boys the tray with a burger.)

Yilona 'It is it' (the other boys are looking down showing that they are envious of the acquisition of the burger by the boy.)

Yebo madoda 'Hey Fellas' (The boy greets the gentlemen seated on the reserved section known as men's table.)

\section{Get a Quarter Pounder with cheese Medium Meal for only R29.90 A small price to pay to sit at the men's table For an Extra 10 Rand get a starter and a Sunday desert}

I'm loving it. (This is the loudest and most visible part but the person who is saying this is not visible and the words and price tag just appear on the screen) In the following section of my discussion, an analysis of the language used in this advert will be provided:

\section{The use of the noun Baba (father)}

When the young boy enters the taxi he says, Baba ngicela ukuhlala kuTV seat. Which 
is loosely translated as 'Sir, may I sit on the free seat?' The use of the noun 'baba' thus, contextualizes the utterance such that it reveals the African context where everyone who is your father's age or around that age is considered your father. In this vein, the advert puts into context the relationship obtaining in the real African perspective and philosophy of respect or ubuntu. This philosophy flows from a Nguni (isiZulu) aphorism: Umuntu ngumuntu ngabantu which means 'a person is a person because of or through others' (Tutu, 2004 pp.25-26; Moloketi, 2009 pp.243).

Ubuntu can be described as the capacity in an African culture to express compassion, reciprocity, dignity, humanity and mutuality in the interests of building and maintaining healthy relationships. Ubuntu is integrated into all aspects of day-to-day life of the African people. It talks to the core values upheld by Africans, especially the black African people, values such as respect, peace, togetherness and responsibility. The application of the concept optimises the indigenous setting of an African.

Thus, the boy is operating within the expectations of ubuntu which makes the boy acceptable and gets a favourable response to his request. If the taxi driver was to be called by the English word 'Sir' a cold and distant form of address would not have the same connotation as Baba.

Thus, the philosophy is explicitly shown by the communication between the taxi driver and the school boy. Here the communication is marked by the respect with which the young boy asks for the free seat from the driver by calling him his father. The exchange between the two interlocutors is as natural as is what normally obtains in an African context. Ballweg (1968 p.84) asserts that:

...by the use of kinship terms to specify relationships, a sort of social grid emerges in which the individual is able to locate himself in relation to other members of his culturally defined kin-group. The position the person holds within the kin network carries with it a set of role expectations that outline the interactional pattern ordinarily associated with the specific set of kin ties.

Therefore, once he is referred to as Baba 'father' the taxi driver responds favourably and accommodates the request of the young boy. This kinship term draws the driver closer to the young boy, thus, creating a relationship which will ensure that whatever the young boy requests from a father, he is sure to get. The young boy's request was granted because by being called Baba 'father', the driver did not want to disappoint his 'son'.

The issue of politeness and 'face-negotiation' also features very positively in the use of the noun Baba 'father' so as to place himself closer to the boy in terms of kinship as espoused in African culture. Brown and Levinson (1987), in their politeness theory, describe 'face' as the public self-image' that all rational people have when engaged in 
spoken interaction. Face consists of two related aspects; positive face and negative face. Positive face includes the want that one's self-image be appreciated and approved; whist negative face is the claim of every member to personal preserves, non-distraction and freedom from imposition, and the desire that their actions be unimpeded by others. Simply put, positive and negative face imply offending someone's 'face' or defending it. By using the noun Baba 'father', the young boy, is acknowledging that he is communicating with someone who is his father's age or older, and also recognises that in speaking to this person he has to be polite, thus, save his face and also that of the driver.

Although the use of the word Baba 'father' assigns power to the driver over the young boy because of his age, the driver does not exercise his power and authority over the young boy, but it is the young boy who uses a different expression of power, that which is known as 'power with' which has to do with finding common ground among different interests and building collective strength. 'Power with' can help build bridges across different interests to transform or reduce social conflict and promote equitable relations. Because of the use of the kinship terms, the politeness strategies of Ubuntu and of face saving, the young boy was able to change the power relations that existed between the taxi driver and himself. The expression of power in this advert goes against what Foucault (1988 p.38) describes as the capacity of an agent to impose his will over the will of the powerless, or the ability to force them to do things they do not wish to do.

\section{The use of the vocative madoda (men)}

The use of the vocative madoda (men) in the advert evokes power in two distinct ways. This is first reflective in the notion of unequal power relations between the addresser and the addressee. The addresser is a minor who uses the vocative to address mature men as if they were his equals. This is so, because the boy has managed to buy the advertised product which the other men seated on the men's table have bought. The boy, therefore, feels equal in status and power to these men. The power of the speaker of the vocative madoda is also realised in the sense that the addresser is in possession of a special product advertised here (the burger) while other boys of his age have failed to acquire due to their limited resources.

For the boy, his ability to buy the burger acts as an initiation into manhood. Thus, the act gives him an edge over the rest of the boys. The use of the vocative madoda 'fellas' is consistent with Brown and Gilman (1960 p.255) who proposes that, power in communication is not reciprocal in the sense that interlocutors in a communicative event cannot both have power. Thus, the assertive way with which madoda 'fellas' is said by the speaker, gives power to the young boy (as a participant in this communicative event) to act in the capacity of a real man. Power is also observed 
where the gentlemen are addressed by the young boy and accept his greeting as normal and consistent with the place and context.

This qualifies the speaker as having more power than that of the boys of his age and this also alludes to the fact that advertising universalizes consumption habits as has been observed by Moyo and Chari (2001). Moyo and Chari's (2001) observation expresses that adverts encourage masses of population to consume basically the same product regardless of the uniqueness of a people's consumption habits. Like globalization, advertising makes popular the burger in this advert and encourages the target cliental to consume it in the manner the advert projects. The advert here projects the advertised burger being consumed by children and men seated on the men's table. Therefore, the advertised burger invites the speaker as young as he is to address others eating the burger as colleagues or comrades by using the vocative madoda 'fellas'.

The use of the vocative madoda 'fellas', shows the power relations tilting in favour of the young boy. Here the boy distances himself from the culture of calling adults male, Baba 'father'. The boy thus, converges to a more acceptable fashion consistent with the consumption habit of the burger by referring to adults' males as madoda (fellas). Even the translation of the vocative madoda 'fellas' if it were not given as fellas it would have been observed as (men) a noun used in spoken mode as referring to basically people of same status. The same status provoked by the vocative madoda (fellas), here is a subtle way of appealing to the commonness or a family/togetherness forged by the consumption of the advertised burger.

The use of the vocative, madoda (fellas) also exudes more power to the speaker in the (boy - group of boys') relationship. This is in view of the fact that the other boys who are not in a position to acquire and consume the advertised burger within the reserved area are not in a position to refer to mature adults as madoda (fellas) or colleagues of some sort for they have no common ground or an interface of any sort like the gentlemen where the boy meets with the gentlemen eating the McDonalds Burger. Therefore, the use of the vocative madoda (fellas) is seen in this light as creating an ideal eating habit for the boys.

But why is it so? Most young boys aspire to be men when they are still young. Therefore, the hot seat boy quickly graduates to be seen in the light of being a real man by occupying the men's table and also addressing other mature men using the vocative madoda (fellas). The use of the vocative by the boy is accepted in the context shown in the advert which marks the acceptance of the boy as part of the group of males seated on the men's table. Thus, the use of the vocative madoda 'fellas' in the face of the group of boys would encourage them to also buy, consume the burger within the reserved area- the men's table for them to also belong to the real 
men- madoda (fellas) being greeted in the advert the man distinguished gentlemen.

In comparing the language used by the young boy when he was requesting a free seat to that which he uses with the gentlemen after he has acquired the burger, we see a change in identity. The boy humbled himself asking for a favour to board the taxi without making a payment, which suggests that the language he uses has opaque power relation in favour of the addresser. Here the boy uses the noun Baba 'father' to refer to the man who is basically of the same age as the ones he calls madoda (fellas) later.

The use of these two nouns Baba (father) and madoda (fellas) shows different power relations. A shift in the power relation is evident in the use of madoda (fellas) in the sense that, the boy has managed to put together his week's fare to buy a burger. The purchasing power the boy has in his pocket changes his diction from calling mature male adults, Baba (father) to calling them madoda (fellas). He now addresses the people he should call baba as madoda. This sudden change in the manner of address signals a change in status. The change assigns power to the speaker where he has risen to a higher status which is the same status as that of mature men and manages to address them as 'fellas'.

The boy's behaviour also assigns testimony to how advert paints modernity with illusion of power in persuading the target market. This is evident in this advert where an illusion of power has been painted through the use of the vocative madoda (fellas) in reference to an economically independent group as equals by an inferior (in terms of economic class) individual. However, the advert has also made use of commands and repetition. The next section explores the use of visuals in this advert.

\section{Visual (Non-Verbal) Elements in Advertisements}

According Bamford (2003 p.1) visual communication in adverts includes gestures, objects, signs and symbols. Some examples of visual signs are dance, hairstyles, monuments, lighting, computer games and interior designs. Boozer, Wyld and Grant (1991) contest that, visual metaphors are used a lot in advertising. They help elaborate the message intended to send through to the audience and increase the chance of persuading them. They are likely to increase the cognition value of the message, which leads to cognitive elaboration when the audience processes the message (Jeong, 2006). Messaris' (1997) study of visual persuasion show that the cognitive elaboration achieved by visual argumentation of an advertisement leads to a greater persuasiveness of visual. Through visual tools, an advertisement can suggest its attitude, the brand attitude, product belief and purchase intention.

In line with visuals, Van Niekerk and Jenkinson's (2011) work forms the basis of 
analysis of this advert. Van Niekerk and Jenkinson (2011) studied typography and layout in print advertising as elements which speak to advertising. Their perspective is more inclined to the visual approach as more forceful and more appealing to prospective advertisers. They posit that graphic tools in print advertising are powerful and are used to arrest the attention of the target market by creating a positive association, a controversy or stimulate some kind of intellectual game. They conclude their observation by pointing out that messages would have already been conveyed by creatively expanding and diversifying the conventional values embedded in certain graphic means and basing the advertisements on prevailing textual norms and the past experiences before the message itself has even been read.

Goddard (2002) maintains that non-verbal aspects of adverts can sometimes want to shock the reader (the text which in this case is part of the advert as read from the screen by the viewer cum-reader) for very good reasons. However, increasingly charities and other fund-raising groups have adopted some of the traditional methods of commercial product advertising to get their campaign noticed, and one of these methods has been the use of disturbing images, as a way of drumming up support for the cause. Goddard (2002) further alludes to the fact that, as readers of adverts, it is pertinent to interpret what is often called paralanguage. This is an umbrella term for those aspects of communication that surround and support verbal language in normal face-to-face encounters. For example, body position, gesture, physical proximity, clothing, touch; eye contact can greatly enhance the meaning being expressed through the verbal language and the visual expressions. The discussion looks at each of these variables and sees how they contribute to the meaning of the advert.

\section{Body Position, Gestures and Facial Expressions}

The body posture of the boy as he receives money from grandmother is consistently poised. The boy as he receives the coins bows and puts his hands together near his chest to show how grateful he is. It is the boy's posture that makes it clear that the money grandmother gives him should be enough for his travel and probably his lunch. The way he receives the money also shows that he is well bred and hopes to make the most out of what he has received. As the grandmother gives the coins she looks on as if she is looking out for dissatisfaction or complains of which she finds none. She then turns back home after she has been convinced by the posture of the boy that everything looks good. Taking this from Jeong's (2006) reading visual metaphors throws a light in the dimension of the worldview of the interlocutors in this communicative event.

The boy after waving for the taxi does not jump in as soon as the taxi stops. Rather he looks up to the taxi driver in appealing for the free seat. He bows again in entering the taxi. He seats while facing the rest of the passengers. As soon as he sits he makes 
himself comfortably but keeps on fidgeting showing that where he is seated is not comfortable. The other boys make their necks long to have a clearer posture of the boy. The body postures outlined above help the character in projecting the realness and character credibility. For example, the way the driver is posed at the steering wheel is so convincing that he looks more like an ordinary taxi driver. Again, the way the boy stops before entering the taxi and negotiate is consistent with one who wants to ask for a favour. It is not acceptable to negotiate on board Jeong (2006).

The way the grandmother posture is as if what is happening is a repeat of an ordinary event. Normally guardians accompany their keep until outside the gate and would look for signs from their keep of being ready to take off with the available transport to school. If the child looks ready to leave the keeper goes back. This therefore has made the advert so convincing thus, persuasive to prospective customers that the advert takes after what normally happens.

The group of boys sit in a worn-out sought of posture while the gentlemen on the men's table are seated elegantly. To give credibility to the advertised burger, the men are seated appropriate with table manners. Their posture therefore convinces the target market that the advertised burger is a status symbol that is associated with real gentlemen. The posture of the boy as he moves towards the men's table with the burger in hand says a lot about the elated status that comes with the possession of the advertised burger. The posture of the group of boys seated sucking ice-cream speaks of the group as without composure and dignity especially when compared to the boy who is now occupying the men's table.

Gestures as nonverbal clues which help in making communication persuasive in the target advert include body movement. The way grandmother drops some coins in the hands of the boy and folds the hand of the boy is affectionate and establishes a close relationship between the boy and the old woman. The old woman further squeezes the boy on the shoulder probably a sign for fare well as the boy heads to wave the taxi and the woman heads back home. The way the boy nods after appealing for help from the taxi driver is so convincing and shows how relieved the boy is of the response he receives from the taxi driver.

The facial expression of the boy as he endures the heat is that of someone who is determined for a purpose. The smile on his face shows how determined he is to persist sitting on the hot seat so that he would secure the advertised burger. His posture and facial expression combine to sell a message. The message of how delicious and important the burger is to the boy. This would persuade the targeted market in the form of other school boys who would want to taste the burger but would be lacking the purchasing power. The smile of the boy encourages the viewers to infer meaning in his enduring. The meaning of the boy's efforts is found in the smile he carries as he moves towards the reserved area with the burger in hand. 
The way the boy's gesture to the hot seat boy as he enters the taxi and sits on the seat facing other passengers demeans the boy's position. The boy later on in the advert gestures the burger in a tray to the other boys who are seated next to the entrance sucking ice cream. This gesture makes a pose of the advertised product being possessed by the hot seat boy. Therefore, in a way the gesture elevates the hot seat boy to someone who is envied by the group of boys. The group of boys somewhat show their desire of the burger by admiration written all over their facial expressions.

The gesture of the taxi driver as (he looks at the boy outside the taxi who is poised as begging for a favour) is soft and compassionate. He gestures to the boy to take a seat and looks ahead to continue with his driving. As the taxi gets to the boy who waves it to stop it sort of hoot which is consistent with the taxi which ply routes in urban areas. Thus, the gestures and expressions which go on within the taxi environment is typical of an ordinary route thus, this goes a long way towards authenticating what is in the advert as real. Once some aspects of the advert are readily acceptable as reality, it follows that even the selling of the burger is as well acceptable as real and what is said of it.

\section{Physical Proximity}

Proximity talks of zones in communication. The zones in communication are defined according to physical distance interlocutors have between themselves as they engage in a communicative event. The closer the distance the closer the relationship and the further apart the distance the distant is the relationship. In the advert, the boy and grandmother share the intimate zone as they speak. This therefore shows how close the two characters are. As the boy asks for an act of kindness, he comes closer to the taxi driver to infer closeness and a kinship kind of relationship. The men seated around the men's table share a social zone as colleagues of some sort. The boy as he walks towards the table, he assumes a commonness with other occupants of the table by sharing the social zone.

The boy assumes a public zone as he takes his seat at the front seat facing all the other occupants of the taxi and can be seen by all in the taxi. Therefore, he is distanced in a way from other occupants of the taxi who have paid their fare and are enjoying comfortable seats. Therefore, the exploitation of the physical distance works towards persuading viewers that what is happening in the advert is not an exception of what usually happens. 


\section{Clothing}

The clothes donned by characters in the advert help in making the advert a reality. For example, the grandmother dress shows that she is full time house keeper. She is dressed in a working dress. Working at home to tidy and work around the house. The taxi driver is geared in a white hat and a tee-shirt a typical dress code for taxi drivers. The school children are dressed in school uniform which marks them as a formal school going lot. The lady passenger is smartly dressed in a floral blouse and is holding onto her bag. The composition of the passengers in the taxi is readily acceptable as any passengers using the morning routes by urban taxis. Thus, characters in the advert are clothed consistent with the roles that they are taking part in.

\section{Eye Contact}

Eye contact in this advert has been exploited to direct attention of viewers to the advertised product. Eye contact has been exploited especially where the boy looks at the group of boys who recognizes him but is surprised to see him holding the McDonalds burger. The boys gaze at him while he looks back full of pride in his accomplishment. The way the group of boys and the hot seat boy look at one another reminds the viewers of the previous relationship between the boys as they are comfortably seated in the public transport and the boy as he inhabits the hot seat. However, now the tables have turned in favour of the hot seat boy where he now heads towards the men's table to feed on a burger while the other boys are having icecream in a fast food outlet. He is celebrated and possible the other boys are seeing sense in being a hot seat boy.

The image makes the targeted audiences and the advert interactive partners in the communication process. It enables them to read the verbal message with a clearer picture of what the message is communicating. Goddard (2002) points to attentionseeking devices, in the TV Seat advert. The occupation of the hot seat and the fugitive position of the boy showing that the seat is hot warrants for attention. Furthermore, visual argumentation requires the audience to interpret the message according to their own construction of meaning. And people are more likely to be persuaded by the proposition they have constructed themselves (Messaris, 1997). In the advert it is the proposition of the viewer that accounts for the interpretation of the use of the visuals as would be discussed below. 


\section{Figure 2: The McDonald's Burger}

The burger is first presented in the tray of the hot seat boy, then as the boy makes a bit of the burger and as a stand-alone image of the burger. In all the three instances the burger has been presented clearly with adequate lightening to make the burger appear very big (in a more than a real size), appetizing and professionally prepared burger. The image of the burger is more than big such that the boy has to use both hands to tag the burger in his mouth. The burger party is as thick as probably four or even five slices beef/chicken (burger parties) put together. Thus, the image of the burger can sell the burger more than what words can say. The image as it stands promises a mouth-watering taste hence the size is enough to qualify the burger as more than medium meal referred to by the wording inscription. The background of the image of the burger illuminates the burger such that one is convinced the image represents the real burger being advertised. This has been made possible by the use of lightening which intensifies and represent the burger in a lovely yellowish-brown courting. Thus, more than having mouthful of words about the burger, the image of the burger distinguishes the advertised burger as a unique kind of a burger which can only be found at McDonalds.

\section{Visuals as a Manipulative Strategy}

The role of advertising visuals includes obtaining attention, creating impact, and stimulating interest from an indifferent audience through conveying a main selling point of products or brands. ${ }^{4}$ In the McDonald's TV advert, the story unfolds visually gaining attention for it is curiosity that would keep the viewer at the edge until the whole advert is viewed. Thus, it can be argued that the visuals in the McDonald's advert here could compel even those who would have had no intention to consume the advert to also have the effect of the advert and finally make a purchase for it is the final objective of an advert. Thus, to act in the shoes of the school boy in the advert who gets his satisfaction after he had a purchase and enjoys the burger seated within the reserved area. Moriarty (1987), relays that, advertising visuals perform two main

${ }^{4}$ https://www.scripps.ohiou.edu/wimcr/vol06/6-3a.html 3 June 2003 
functions - literal and symbolic.

Moriarty (1987) further communicates that, literal visuals provide factual information on products or services, and symbolic visuals perform an indirect role to connect the images of products or services with the meanings that are appropriately assigned to them. Observing this perspective, TV Seat advert visuals are indeed performing the said two functions. The literal function is the price tag which is R29.90 as well as the specified product being sold in this respect the McDonald's burger. The symbolic function is the presentation of the image or the picture of the advertised burger in the exaggerated size. Therefore, the exaggerated size agrees with what the burger is meant to represent. Thus, the image attracts the prospective customer and act as appetizer to the viewer by merely looking at the image of the burger one would salivate or want to taste it.

Visual appeal always had a prominent place in advertising. ${ }^{5}$ The old saying is that a picture is worth a thousand words; so many advertisers usually try to visually communicate messages, rather than bog down the receiver in heavy text (Hecker \& Stewart (1988 p.2). In this vein instead of creating a narrative about the advantages that accrue with the purchase of the McDonald's burger in this advert, the hot seat story is shown where the boy endures the heat for almost a week's travel to school only to work towards purchasing a burger that is indeed worth his effort from the look of it. Furthermore, the boy is visibly seen joining other gentlemen seated within the reserved area "the men's table". The visuals thus, tell a clear story of working towards buying a burger and accomplishing the goal of finally getting to buy the burger and eat it within the reserved areas. It can be argued that, the visuals appeal to both the literate and the illiterate. It can also be forwarded that the images in the TV Seat can be discerned by the deaf and dump who can discern what is happening in the advert from the pictures/images in the advert.

The association function of the visual represents an effort to relate the product with consumers' lifestyle, typical person's character, and everyday use situation. ${ }^{6}$ It is an indirect way of identification or description of the product to persuade consumers to try their products. In TV Seat advert the burger is associated with the working-class man in white coats. These men are not just common man in the street but they are meant to represent the intellectuals who do experiments or who work in some laboratories and are having the McDonald's burger as their lunch. The men here occupy the men's table where anyone who has the potential to buy the burger gets to sit within these areas.

Visuals never want to directly describe or identify product characteristics or their

5https://www.scripps.ohiou.edu/wjmcr/vol06/6-3a.html 3 June 2003

6 https://www.scripps.ohiou.edu/wimcr/vol06/6-3a.html 3 June 2003 
usage, but visuals usually entice consumers to try the product through indirect explanation of potential consumers' lifestyle and situations in which the product is certainly tried. ${ }^{7}$ Thus, in the TV Seat the advantage or the delicacy of the burger is not described but is seen to be favoured by gentleman and school boys alike. The boy who has managed to buy the burger is shown in a more advantageous position and a prestigious position as compared to the other boys who were laughing at him as he was saving the taxi fare towards buying the burger.

Thus, the advantages that accrue with the purchase of the burger is that of enhancing one's status and getting to be respected by people who formally thought they were better-off than the boy. The example here is that of the case of the boy versus the other school boys. Thus, the burger elevates the social status of the boy by associating him with the men's table. The gentlemen shown to be occupying the men's table entice other boys and men to want to join such a group of eligible gentlemen who have a special place to feed. All these aspects are witnessed by the viewer. Thus, the visuals can persuade the potential customers to identify with the people of the class shown in this motion picture/video.

Moriarty (1987) claims that, when advertisers think that they need to appeal to consumers' rationality, they use literal visuals, and, conversely, when they think that they need to appeal to consumers' emotions they use more symbolic visuals. This is how the contrasting application of two conflicting role of ad visuals looks like. When this result is connected to the types of ad visuals, photograph as opposed to illustration, it becomes evident that the rational approach employed more photographs while the emotional approach embraced illustrations more. In the TV Seat advert, it can be argued that the advertisers taped on the literal visuals where photographs of the advertised burger are shown though with the exaggerated size for clarity and appeal. It is not illustrated anywhere how it is supposed to be consumed and when. The kinds of visuals that are used make it possible for the viewers to infer the time and the type of people who must be seen eating the burger. The visuals sell the burger to anyone who has the potential to pay the required price. This is so because of the visuals that show the young and mature adults universalizing their eating habits. Thus, the visuals appeal to all the economic classes and assure them that it is possible to buy and eat the burger as witnessed in the advert.

\section{Visual Semiotics as Persuasive Aspects of Adverts}

Visual semiotic is mainly concerned with how images are "read" and how meaning is drawn from them. The same source points to the fact that, visuals contribute to the three Hallidayan metafunction -ideational, interpersonal and textual that visual signs

7https://www.scripps.ohiou.edu/wjmcr/vol06/6-3a.html 3 June 2003 
perform in order to realise meaning. Castle (2007 p.200) points out that, linguistic signifiers are largely symbolic because the link between the sign and the object to which it refers is entirely arbitrary whereas visual signifiers can all be three: iconic because they look the object they represent, in the McDonalds TV advert the advertised burger image looks like the picture/ image that represent it. In terms of accessibility, the image is accessible even to those that had no idea what a burger is and how it looks like. Thus, in terms of persuasion, the burger stands to persuade the target market more by its visual appeal than its linguistic representation that is the word burger.

In visuals, the sign other than being iconic can also be viewed as indexical because they can metonymically stand for something else. The advertised burger is representing the kind of food that McDonalds as a company is known to produce. It is the brand name for McDonalds. The company is known for its exceptionally tasty burgers. Therefore, the visual showing the burger is representing the business of McDonald's company. Thus, the visual as discussed under visuals and the use of colours, is eye catching and appealing for it is supposed to be associated all the times with what is known to be produced by McDonald's Company only. Finally, the sign visually can also be symbolic because the sign can represent an idea or association that is arbitrary rather than literary.

In line with Kress \&Van Leeuwen (1996) perspective, in McDonald's TV advert the arbitrary represent of a burger with gentleman is made possible by the fact that the burger is offered together with the men's table. Thus, the image of the burger in a tray can only be comfortably consumed within the shown reserved area. Thus, it can be argued that the wording description cannot achieve same effect to the three-identified appeal of the visuals. The iconic role of visuals in advertising that is the direct likeness to reality makes the burger in McDonalds and any other visuals of advertised products appear more "truthful" than written text and enable them to play a formidable role in playing the factuality of persuasion in adverts.

As provided by the analysis of the visuals presented above and the manipulation of colour in the advert, Kress and Van Leeuwen (1996) have provided a detailed reading of images in terms of Halliday's three metafunctions. In these scholars' perspective, field that is the ideational meaning in images is constructed by the participants and the setting conveyed in the composition and content of the short. In TV Seat advert the deliciousness of the McDonalds advertised burger is made clear by the images of the story of the school boy who sits on the hot seat to have his taxi fare at the end of the week to buy the McDonalds burger.

The money saving journey is not clear until the school boy acquires the advertised burger. The story is so realistic and convincing as it is visually witnessed. Thus, the facial expression of the boy as he travels on the hot seat talks to enduring of the 
unbearable position he decides to travel in for the whole week. The smile and springy kind of step that is witnessed of the boy speaks to the anticipation and fulfilled dream of the young boy. This description and appeal can only be discerned through the visuals and this therefore gives more power of persuasion to the visuals. The advert can actually encourage other school boys to act as the protagonist in the visuals and have their burger at the end of the week.

The iconic, symbolic and ideational aspects as proffered by Halliday are concepts which inform this section of the discussion. In McDonalds TV advert and other images clothing and "props" indicate different fields to which participants can be assigned. For example, the school boy and other passengers in the taxi show different fields with participants involved in different activities. The taxi driver, the grandmother, the food outlet, the reserved area and the advertised burger in the tray all these have a significant part that integrate to work towards the overall meaning of the total visual/picture.

Thus, clothing and props are not merely iconic but have also taken on a symbolic value as signifiers. This can be the case of the school uniform used by the children in the taxi this identifies them as school going children, the dress donned by grandmother makes her full-time house keeper who does not go out to work. The time grandmother accompanies the school boy is the time those that go out to work some places would be dressed for work. She on the contrary looks like she will be busy in the home. The taxi driver with his white hat marks him like any of the taxi drivers who ply the routes in urban areas. The gentlemen in the food outlet look like working lot who has just snatched a moment to go out for lunch from their busy schedules. Thus, these different fields showing real fields work towards authenticating the advert as reality obtaining on ground.

Tenor of an image involves interpersonal meanings involving the participants, the producer of the image and the consumer can all be in play. Body language and facial expressions form iconic that indicate attitude or emotion. Here the smile of the boy as he holds a tray with burger goes to indicate how happy and what the advertisers wish to achieve by the images that have been shown before and the current images of the boy and the burger. The body language of the boy positioned eating ice-cream is without composure and become felon as they witness the hot seat boy with the burger in a tray. The step of the hot seat boy with the burger talks of a change in status of the boy.

\section{Conclusion}

This paper has analysed the use of language and visuals in the McDonalds advert. Of importance in this discussion is how language in the form of vocatives and commands 
has been used to show unequal power relations. Linguistically, language has demonstrated that ideology and hegemony are embedded in the linguistic choice made in the advert. Language has dual characteristics. From the foregoing discussion it is evident that language flaunts one's identity and ones' culture.

Therefore, in this advert the characters use of language reflected on their identity, culture and belief systems. Non-verbal aspects such as visuals and the use of colour reflected on the choices of reality that the advert has made to project. It is pertinent to note that the analysis of the visuals and the language help in showing the unequal power relations, hegemony and ideology. The advert appears as a unit therefore should be analysed as such. To only highlight the language aspects of the advert would not bring out other elements highlighted by the visuals. The same can be said of the visuals only analysis. Therefore, the blended approach made possible by CDA can be arguably be embraced as an all-inclusive approach to text analysis.

\section{REFERENCES}

Ballweg, J. A. 1969. Extensions of Meaning and Use for Kinship Terms. American Anthropologist. 71: pp.84-87.

Bamford, A. (2003). Visual literacy White Paper. London: Sage.

Brown, R. and Gilman, A. 1960. Style in Language-Linguist, London: Sage.

Castle, G. 2007. The Blackwell Guide to literary Theory. Oxford: Blackwell Publishing

Fairclough, N. \& Wodak, R. 1997. Critical Discourse Analysis. In TA Van Dijk (ed.) Discourse as Social Interaction. London: Sage.

Foucault, M. 1980. Power/Knowledge: Selected interviews and other writings, 19721977. New York: Pantheon.

Goddard, A. 2002. The Language of Advertising. London: Routledge.

Hecker, S \& Stewart, D.W. (eds.) 1988. Nonverbal communication in Advertising. Lexington, Mass: Lexington Books.

Jeong, S. 2006. Visual Metaphor in Advertising: Is the Persuasive Effect Attributable to Visual Argumentation or Metaphorical Rhetoric? Journal of Marketing Communications, 14(1), 59-73. Doi: 10.1080/1469701070171748.

Jongore, M. 2017. An exploration of manipulative use of language and visuals in selected TV Adverts. (Unpublished PhD thesis), Pretoria: University of South Africa. 
Linguistic and Extra-Linguistic features of SABC indigenous language adverts: A critical ...

Kress, G. \& van Leeuwen, T. 1996. Reading Images: The Grammar of Visual Design. London: Routledge.

Leiss, W. 1990. Social Communication in Advertising. London: Routledge.

Leiss, I., Kline, S. \& Jhally, S. 1990. Social Communication in Advertising: Persons, Products \& Images of Well-being. New York: Routledge.

Lemke, J. 1995. Analysing Verbal Data: Principles, Methods, and Problems London: Routledge.

Less, W. 1990. Social Communication in Advertising. London: Routledge.

Levin, D. M. 1988. The opening of vision: Nihilism and the postmodern situation. London: Routledge

Moleketi, G. F. 2009. Towards a common understanding of corruption in Africa International Journal of African Renaissance. London: Taylor \& Francis.

Moriarty, S. E. 1987. A content analysis of visuals used in print media advertising. Journalism Quarterly, Available at www.sagepub.com

Moyo, D. \& Chari, W. 2001. Media Policy in a Changing Southern Africa: Critical reflections on media reforms in the global age. Pretoria: UNISA Press

Moyo, D. 2001. Broadcasting Policy Reform and Democratization in Zambia and Zimbabwe, 1990-2005: Global Pressures, National Responses, (Unpublished PhD Thesis) Oslo: University of Oslo.

Tutu, D. 1994. The rainbow people of God: The making of a peaceful revolution. New York: Doubleday.

Tutu, D. 2004. God Has a Dream: A Vision of Hope for our Time. New York: Doubleday.

Van Niekerk, A. \& Jenkinson, A. 2013. The use of sexual controversy in South African advertising: A pragmatic analysis. Language Matters: Studies in the Languages of Africa, 44:2, pp.29-46.

Vestergaard, T. \& Schrøder, K. 1985. The Language of Advertising Oxford: Blackwell. 